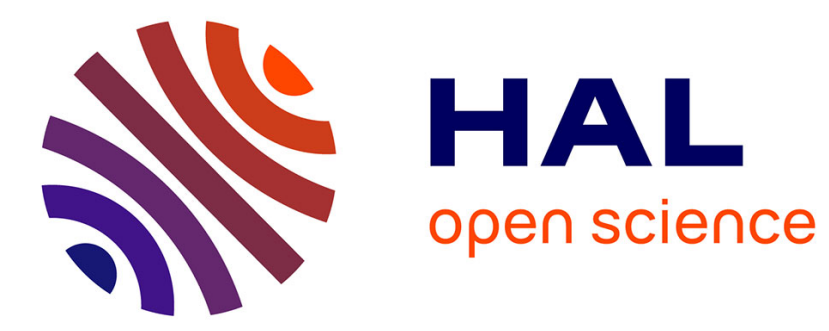

\title{
Strategies and needs of blind pedestrians during urban navigation
}

Lucie Brunet, Françoise Darses, Malika Auvray

\section{To cite this version:}

Lucie Brunet, Françoise Darses, Malika Auvray. Strategies and needs of blind pedestrians during urban navigation. Le travail humain, 2018, 81 (2), pp.141 - 171. 10.3917/th.812.0141 . hal-02398012

\section{HAL Id: hal-02398012 \\ https://hal.science/hal-02398012}

Submitted on 6 Dec 2019

HAL is a multi-disciplinary open access archive for the deposit and dissemination of scientific research documents, whether they are published or not. The documents may come from teaching and research institutions in France or abroad, or from public or private research centers.
L'archive ouverte pluridisciplinaire HAL, est destinée au dépôt et à la diffusion de documents scientifiques de niveau recherche, publiés ou non, émanant des établissements d'enseignement et de recherche français ou étrangers, des laboratoires publics ou privés. 
The aim of the exploratory study reported here was to investigate in depth the needs and strategies (heuristics and procedures) of blind pedestrians during navigation in an unknown urban environment. Blind participants had to prepare for and then complete a two-kilometer route. The participants' requests for information and verbalizations were recorded before and during navigation and they were further detailed with individual interviews afterwards. The results revealed the influence of journey-organization habits on the strategies that were adopted and on the required needs. In addition they highlighted those resources (e.g., other pedestrians) and constraints (e.g., temporal) that are shared by all participants, and those resources (e.g., use of specific navigation tool) and constraints (e.g., anxiety) that vary with participants' journey-organization habits. Based on the results of this study, we draw recommendations concerning the design of navigation aids for blind pedestrians, in order to enhance their acceptability by the target population.

Keywords: Navigation, Blindness, Needs, Strategies, Visual impairment, Spatial Cognition.

RÉSUMÉ

Alors que la recherche en sciences cognitives s'est focalisée sur l'identification de systèmes efficaces pour guider les piétons aveugles, peu d'études ont examiné les stratégies de navigation dans leur ensemble, prenant en compte l'articulation entre la phase de préparation et la phase d'exécution de l'itinéraire. La présente étude a cherché à aborder cette question, en s'appuyant sur la perception spatiale, la cognition spatiale et la navigation humaine. L'étude exploratoire présentée ici vise à étudier de façon fine les besoins et les stratégies (heuristiques et procédures) 
que les piétons non-voyants mettent en oeuvre au cours d'une activité de navigation dans un environnement urbain inconnu. Six participants non-voyants ont préparé et réalisé un parcours de deux kilomètres en ville. Ce parcours a été divisé en segments, correspondant à chaque intervalle entre chaque point de réorientation. Les participants ont été divisés en trois groupes, en fonction de la manière dont la phase de préparation de l'itinéraire était réalisée : avec des aides technologiques uniquement, avec l'assistance d'une tierce personne, ou bien sans aucune préparation. Les demandes en information des participants et les verbalisations ont été enregistrées avant et pendant la navigation, ainsi qu'au cours d'un entretien individuel mené à l'issue du trajet. Le contenu de ces demandes d'information a été analysé sous l'angle du degré d'anticipation qu'elles reflétaient. Le degré d'anticipation correspond au nombre de segments qui sépare le point où le participant se trouve et l'endroit sur lequel il cherche des informations. Les résultats ont révélé l'influence des habitudes de planification du déplacement (préparation sans aide humaine, préparation avec aide humaine, ou sans préparation du tout) sur les stratégies qui ont été adoptées et sur les besoins en information nécessaires. En outre, les résultats ont souligné que certaines ressources (par exemple, les autres piétons) et certaines contraintes (par exemple, temporelles) sont mobilisées et prises en considération par tous les participants. Inversement, d'autres ressources (par exemple, l'utilisation de l'outil de navigation spécifique) et contraintes (par exemple, l'anxiété) varient en fonction des habitudes de planification adoptées par les participants. Cette étude nous permet de formuler des recommandations concernant la conception des aides à la navigation pour les piétons non-voyants, qui permettraient d'améliorer l'acceptabilité de ces outils par cette population.

Mots-clés : Navigation, Non-voyants, Analyse de l'activité, Stratégies, Handicap visuel, Cognition Spatiale.

\section{INTRODUCTION}

According to the World Health Organization (WHO, 2017) around 253 million people live with visual impairment, with 36 millions of them being blind. Enhancing the autonomy of visually impaired or blind individuals is, therefore, an important goal for society (CERTU, 2008). Although most blind individuals are willing to use assistive technology, their needs remain unfulfilled (Gold, Simson, \& Zuvela, 2005). The limitations of traditional navigation aids (white cane and guide dogs) and the availability of context-sensitive technology have stimulated the development of navigation aids for the blind, especially, GPS-based devices. As a result, numerous navigation aids for visually impaired individuals are currently available. But most of these aids focus on avoiding potential obtacles recognition and on recognizing the nature of nearby moving and static obstacles (Mekhalfi et al., 2016, p. 129). The extent to which these devices fulfill their goal of helping blind individuals navigate in complex environments (e.g., a city) remains limited.

One of the main reasons for the lack of acceptance of navigation aids relates to users' lack of control on itinerary preparation, which is 
performed automatically based, on pre-defined starting and end points. The itinerary is described in a segment-wise fashion, making it difficult for the user to form a mental representation of the itinerary in its entirety. While research in the cognitive sciences has focused on identifying effective methods for guiding blind pedestrians (for a review, see Gallay, Denis, \& Auvray, 2013), few studies have examined navigation strategies as a whole, taking into account the articulation between the journey-preparation phase and the subsequent navigation phase. The present study sought to address this issue, drawing on spatial perception, spatial cognition, and human navigation.

\section{I.1. Design OF URBAN-NAVIGATION AIDS: FROM A TECHNO-CENTRIC APPROACH} TO AN ERGONOMIC APPROACH

Several factors limit the development and the diffusion of navigation aids for blind users. For example, issues with the reception of satellite signals limit the reliability of GPS-based devices (resulting in inaccurate localization information) and they induce constraints on the environments in which such devices can be used. The shortcomings of GPS-based navigation aids for pedestrians have been documented in various studies (Baudoin et al, 2005; Denham, Leventhal, \& McComas, 2004; Kammoun, 2013; Spérandio \& Uzan, 2004; Sanchez \& Saenz, 2010). The lack of user-friendliness, personalization, and a poor esthetics further contribute to limit the wide adoption of these devices (Arnold, Pesnot-Lerousseau, \& Auvray, 2017). Finally, the combination of complex technologies and a relatively small market, results in relatively high costs.

Many studies have been devoted to the design and the evaluation of navigation aids. For example, Klatzky, Giudice, Bennett and Loomis (2014), Loomis, Marston, Golledge, and Klatzky (2005), as well as Loomis and Philbeck (2008), have evaluated innovative technologies, such as binaural sound, in well-controlled laboratory environments and in more ecological settings. Mekhalfi et al. (2016) designed a prototype, made of cameras and sensors placed on the chest, that allows both recognition and navigation functions. This device provides blind people with navigation and obstacle avoidance aids. However, this prototype is restricted to indoor environment and it does not address the steps of route planning and wayfinding. Cecilio, Duarte and Furtado (2015) designed the system BlindeDroid whose aim is to guide blind people in large indoor environments, such as shopping centers or public office buildings. Their system offers an aid for short distance wayfinding, but it does not take into account the phases during which impaired people must plan and organize their journey.

All these studies focused mainly on navigation performance. In addition, most of them focused on the "mobility" phase (Heuten, Henze, Boll, \& Pielot, 2008). The way blind people go through the "preparation" phase has often been neglected (Miele, Landau \& Gilden, 2006). Thus, it remains a wide range of investigations to be performed on navigation as a whole. Device acceptability should take into account the qualitative aspects of blind users' experience, as well as their interactions with the device in real 
environments. As was noted by Plos, Buisine, Aoussat and Dumas (2007), blind users' needs are rarely analyzed, and when they are, the results of these analyses do not allow for useful recommendations directly useable by member of the assistive-device design team (see also Benetti \& Collignon, 2014). This limits both the efficiency and the acceptability of current assistive devices.

The French law of Febuary 11, 2005, which requires "equal rights, opportunities, participation, and citizenship for persons with a handicap" emphasizes the fact that handicap results from an interaction between, on the one hand, a disability or health issue that limits people's activities and, on the other hand, an environment that includes personal as well as contextual factors (such as habits, education, culture, profession). Identifying the various factors that underlie impaired people's navigation activities, and identifying the most important ones, in order to design ergonomic navigation aids, is a complex issue. Plos et al. (2007) argued in favor of the Canadian approach (such as the one developed in Fougeyrollas, Cloutier, Bergeron and Côté, 1998), which considers handicap as a whole. This approach emphasizes the fact that handicap does not result from a mere disability but rather from its interactions with numerous other variables. These variables can be sorted into three categories: (i) personal factors (e.g., age, gender, capacity, anthropometric characteristics, sociocultural identity); (ii) environmental factors (e.g., social environment, urban architecture, assistive technology); (iii) way of life (e.g., everyday activities and social habits, personal values and sociocultural context).

Although researchers agree on the importance of the plurifactoriality underlying blind individuals' activities, so far, most studies have focused on the psychological determinants of this activity, such as stress (Wolff, Cabon, Uzan, Nelson \& Couix, 2006) presentation of information (Gaunet \& Briffault, 2005), or allocentric versus egocentric spatial reference frame, (Arnold, Spence, \& Auvray, 2016; Becchio, Del Giudice, Dal Monte, Latini-Corazzini, \& Pia 2011; Gallay et al., 2013; Kessler \& Thomson, 2010; Kessler \& Wang, 2012). Contextual factors, such as urban environment constraints, aids and resources, are often neglected. Moreover, previous studies have put emphasis either on the phase of preparation of the itinerary or on the phase of actual navigation, without investigating how these two parts of navigation are linked.

\section{I.2. Psychological Dimensions of NAVigation ACtivities}

The psychological and cognitive dimensions of navigation in blind individuals have been extensively investigated (Afonso et al., 2010; Denis, 2018; Deroy, Fasiello, Hayward, \& Auvray, 2016; Thinus-Blanc \& Gaunet, 1997; Nelson, Wolff, Cabon, Uzan, \& Couix, 2006). Previous studies underlined the important role of the following factors: the cognitive representation of space, the age at the onset of blindness, temporal constraints, and the way in which information is presented. The main findings of these studies are summarized below. 


\section{I.2.1. Blindness and spatial cognition}

For blind individuals, orientation and navigation are complex tasks and they often induce stress and fatigue (Nelson et al., 2006). Even when they are helped with a guide dog or a white cane, navigation is usually more difficult when the itinerary is not known in advance. The difficulty varies depending on environmental factors such as the density of the population, the weather, architectural constraints, the presence or absence of landmarks. There is important inter-individual variability in the perception of these difficulties.

Congenitally blind individuals must rely on sensory modalities other than vision to build spatial representations (Schinazi, Thrash, \& Chebat, 2016). The normally functioning visual organ provides multiple sources of information (including near and far distances) within a very short time frame. Blind individuals must re-create this process by integrating information across multiple sensory modalities, including hearing, touch, and proprioception. This is a costly and time-consuming cognitive process. Since blind individuals do not have access to information concerning distant objects (O'Brien \& Auvray, 2014; Proulx, Todorov, Taylor Aiken, \& de Sousa, 2016), they must integrate information sequentially, as this information becomes available, during navigation. For instance, a blind individual will experience walking on grass, then on a road, then on pavement, whereas a sighted individual can apprehend the succession of terrains all at once and form a global visual scene at a glance.

Because blind individuals acquire and integrate spatial information sequentially, they tend to organize this information in an egocentric fashion, remembering the positions of spatial elements in relation to the position of their own body (see Arnold, Spence, \& Auvray, 2017). By contrast, sighted individuals tend to organize their spatial representations allocentrically, meaning that the positions of spatial elements are encoded independently from the observer's position. The distinction, which was introduced by O'Keefe and Nadel (1978), between "first-person" vision (egocentric, road-like perspective) and "third-person" vision (allocentric, map-like perspective), is especially meaningful when applied to the spatial-representation abilities of blind and sighted individuals. Noordzij, Zuidhoek, and Postma (2007) have investigated the characteristics of mental representations of environments, which were described verbally to blind and sighted participants, either as a map or as a road. The authors used a recognition task with priming in which participants were presented with the names of two elements. These elements were either present in, or absent from, the initial verbal description of the scene. The participant's task was to indicate as quickly as possible whether the second element was present in the previously described environment. The results showed that, when the two elements were present in the description, a priming effect was observed in both blind and sighted participants, whereby response times were faster when the two named elements were spatially proximal than when they were far apart. This effect was not observed in either group when the words were close in text but far in the initially described space. Therefore, the authors concluded that blind individuals can form non-verbal, spatial 
mental representations of verbally described environments, and that these spatial representations contain the same metric information as those of sighted individuals.

The second task assigned to participants involved comparing distances between elements in the environment. The results showed a similar effect in blind and sighted people: the larger the difference between the two tobe-compared distances, the longer the response times. This suggests that blind and sighted individuals have a similar organization of spatial mental representations of the environment. However, a study of the influence of the type of description revealed that road-like descriptions led to more robust mental representations of space in blind participants, whereas sighted individuals preferred map-like descriptions. Similarly, Rieser, Gum, and Hill (1986) found that when a navigation task requires a change in perspective or spatial inferences (that relies on allocentric reference frames) congenitally blind people do not perform as well as sighted and late blind individuals. These finding suggest that the lack of visual input leads blind individuals to organize their representations of space egocentrically, at the expense of allocentric representations (for similar claims, see also Arnold et al., 2017-b; Denis, 2018). It however seems that this difference in allocentric versus egocentric representations differs as a function of the scale of the environment. In blind persons, egocentric spatial representations are favored particularly in small-scale space, when the body offers a stable anchor point (Iachini, Ruggiero, \& Ruotolo, 2014).

It has to be mentioned here that in some spatial tasks, the use of an egocentric perspective is sufficient to succeed. When it is the case, sighted and blind individuals can obtain comparable performance. For instance Loomis et al. (1993) compared spatial memory performance in blind and blindfolded sighted participants. The participants in this study were accompanied along a straight or curved path, and they were requested to reproduce it. There was no significant difference in performance between blind and sighted people. This suggests that visual impairment does not entail the estimation of directions and the estimation of distances between elements of an environment that has been physically explored. This result can be due to the fact that reproducing a physically experienced itinerary is based on kinaesthetic and vestibular memory, corresponding to an egocentric frame of reference. On the other hand, when the task involves encoding spatial information that has not been physically explored, or when it involves spatial inferences or changes in perspective, then differences are more likely to appear between blind and sighted people (Rieser et al., 1986).

It should be mentioned that some studies linked spatial cognition with blindness aetiology. For instance Eardley, Edwards, Malouin and Kennedy (2016) found in a task assessing allocentric capacities that blind people with retinopathy of prematurity performed lower than sighted and early blind participants, who obtained similar result. According to the authors, it's not visual impairment alone that induces impaired allocentric spatial performance but visual impairment together with retinopathy of prematurity. The existing literature reports sometimes a negative and sometimes a lack of influence of blindness on performance in allocentric spatial processing. 
This result allows highlighting this apparent contradiction in that, to give a fine-grained account on the differences in spatial cognition between blind and sighted people, blindness should not be considered alone, but taken with its aetiology.

\section{I.2.2. Information-presentation modes}

Various approaches can be used to assist navigation in visually impaired individuals: tactile maps, satellite-based guiding technologies, verbal guiding, binaural sound (or $3 \mathrm{D}$ sound, made possible by the use of stereo headphones and an electronic compass), spatialized verbal information, and systems combining tactile and auditory information. Verbal information has been identified as the best way of guiding navigation in blind individuals, for various reasons. Firstly, according to Gaunet and Briffault (2005), verbal instructions make it possible to describe an unknown itinerary in the most adapted way. A study by Denis and Zimmer (1992) showed that it is indeed possible, using solely verbal information, to induce in blind individuals spatial mental representations that can be used to guide actions. Secondly, verbal guiding makes it possible to describe complex environments more precisely than when using tactile maps (Avraamides, Galati, Pazzaglia, Meneghetti, \& Denis, 2013; Richard, Vaz-Cemiglia \& Portalier, 2004). For example, maps of a train station, an urban plaza, or a large roundabout contain a wealth of information, and a substantial cognitive effort is required in order to apprehend and memorize this information via tactile exploration. Thirdly, using the auditory channel makes it possible to deliver information progressively during the course of navigation, thus limiting memory load.

\section{AIM OF THE STUDY}

Most of previous studies, as those described in the above section, seek to identify the cognitive competences of blind individuals. In these studies, contextual factors, which are crucial in real-life navigation activities, receive little attention. In our study, we chose to adopt an ergonomic approach, which emphasizes the situated dimension of human cognitive activities (Leplat, 1990; Arnold \& Auvray, 2017). The aim is not merely to reveal individual's cognitive abilities to perform a particular navigation task, but to emphasize how individual's performance is shaped by external constraints. Moreover, this performance also depends on the expertise acquired through repeated practice.

The goal of our study is to shed light on some of the contextual determinants of a navigation activity, and to highlight some of the strategies used by blind individuals during this activity. Thus, our exploratory study aims at highlighting the contextual factors that influence this expertise, and at comparing individual navigation strategies of blind individuals. 
Finally, given that analyzing blind individuals' needs during navigation is an important pre-requisite to formulating design recommendations for user-centered navigation-aid devices, an output of this study was to promote the development of such devices.

A pre-requisite of our study was to collect data from visually impaired volunteers, used to perform pedestrian urban journeys on their own. Reaching such a population is not easy, cutting down our sample size. This is why our study must be seen as an exploratory one. Rather than conducting a case study, and following Sanchez and Saenz (2010), as well as Almeida, Martins and Lima (2015), we built a "quasi-experimental" design, so as to examine the effect of this "preparation mode" factor.

\section{METHOD}

\section{III.1. PARTICIPANTS}

Six blind individuals (4 females and 2 males), aged 34-64 years $(M=50)$, participated in the study. As presented in Table 1, these volunteers were used to navigate on a daily basis. Therefore, they can be considered as navigation experts. All of them use a white cane; only two have a guide dog. Four of them (participants A, B, C, D) used navigation aids, especially the Kapten system, which is a GPS navigator for blind people. Participant $\mathrm{C}$ was used to prepare her journeys by recording all the information collected from google.maps and from someone helping her. During the mobility phase, she listened to these recorded information, to find her way.

TABle 1. Demographic data and participants' profil.

TABLEau 1. Données démographiques et profil des participants.

\begin{tabular}{|c|c|c|c|c|c|c|}
\hline Participant & $\begin{array}{c}\text { Deficiency } \\
\text { Early or late } \\
\text { blind }\end{array}$ & Sex & Age & $\begin{array}{c}\text { Usual travel } \\
\text { assistance }\end{array}$ & $\begin{array}{c}\text { Usual } \\
\text { navigation } \\
\text { aids }\end{array}$ & $\begin{array}{c}\text { Travel } \\
\text { frequency }\end{array}$ \\
\hline$A$ & Early & $\mathrm{F}$ & 64 & White cane & Kapten & Everyday \\
\hline$B$ & Late & $\mathrm{M}$ & 49 & White cane & Kapten & Everyday \\
\hline$C$ & Late & $\mathrm{F}$ & 62 & $\begin{array}{c}\text { White cane } \\
\text { Guide dog }\end{array}$ & Recorder & Everyday \\
\hline$D$ & Late & $\mathrm{F}$ & 58 & $\begin{array}{c}\text { White cane } \\
\text { Guide dog }\end{array}$ & Kapten & Everyday \\
\hline$E$ & Late & $\mathrm{F}$ & 25 & White cane & None & Everyday \\
\hline$F$ & Early & $\mathrm{M}$ & 43 & White cane & None & Everyday \\
\hline
\end{tabular}




\section{III.2. Design SETTING}

Blind pedestrian navigation begins with the preparation of the itinerary (in this paper, PREPARATION phase). It continues with the journey itself (in this paper, MOBILITY phase), and it ends when the destination is reached.

We hypothesized that some strategies used to prepare the itinerary (during the PREPARATION phase) promote higher navigation performance (during the MOBILITY phase) than others. Multiple criteria, relating to different dimensions of navigation activities, can be used to evaluate navigation performance. For example, one can consider the total duration of the journey (including the PREPARATION phase and the MOBILITY phase) or the number of times that the participant requested information (as an indicator of the participant's degree of autonomy).

During the very first step of the study, it was found that blind pedestrians organize their navigation in an unknown environment according to three different manners - which we hereafter refer to as preparation mode: either WITHOUT human assistance; or WITH human assistance; or with NO PREPARATION at all. Participants in our study differed in their habits in route planning:

- Participants A and B were used to rely on technological aids, such as GPS, to plan their route and to execute their journey;

- Participants C and D were used to plan their route with human assistance, and had a dog to help them in the execution of the journey;

- Participants E and F did not plan their route and manage by themselves the execution of the journey.

According to their habits in route planning, participants were divided into three groups. Depending on their group, participants were requested to behave differently during the preparation phase of the experiment:

- Group withouT HUM-AID: participants A and B had to proceed the preparation phase without human assistance ;

- Group WITH HUM-AID: participants C and D had to proceed the preparation phase with human assistance;

- Group NO-PREPA: participants E and F did not go through any preparation phase.

None of the participants knew the route nor the area, beforehand. None of them lived in the area where the experiment has been conducted.

\section{III.3. SCENARIO AND PROCEDURE}

We developed an experimental protocol based on a navigation scenario to be played in a real urban environment. An important feature of the scenario is that it includes the two phases typically involved in a pedestrian navigation activity: the PREPARATION phase and the MOBILITY phase.

The navigation environment for the experiment was the Paris neighborhood "Convention." This is a typical urban, residential environment, with moderate automotive traffic. An itinerary was chosen, which involved all facets of pedestrian navigation in complex urban environments. It included 
multiple street crossings, curved streets, a square and four "obligatory crossing points" through which the participant had to pass: (1) a metro station (as the starting point); (2) a friend's house (3); a Tax Office; (4) and another metro station, which was used as the endpoint. This approximately 2-kilometers journey took between 15 and 20 minutes for sighted individuals (the experimenters), and between 45 and 60 minutes for the blind participants.

The experiment was tested with two visually impaired people (not included in the main study). Improvements were made on different points of the procedure. Scenario elements were provided verbally to each participant at the beginning of the experiment, that is before the preparation phase for WITHOUT HUM-AID and WITH HUM-AID groups, and before the mobility phase for the NO-PREPA group.

\section{III.4. DATA COLLECTION}

The experiment involved two data collection methods: (a) audio-video recording throughout preparation and journey and (b) individual interviews before and after the journey.

\section{III.4.1. Fourney preparation and realization}

Participants were first given the itinerary-scenario. The experimenter transmitted verbally the following keypoints: point of departure (Convention subway station), two intermediary destinations to go through (two addresses: 14 rue Bausset and 41 rue Violet) and the point of arrival (La Motte Piquet subway station). Then, participants were asked to get prepared for the journey:

- The participants in group WITHOUT HUM-AID prepared on their own using the web-based tools for itinerary preparation that they were familiar with (e.g., Google Map, Mappy). They were asked to think aloud during this preparation. The experimenter was in charge of recording these verbalizations.

- The participants in group WITH HUM-AID received help from the experimenter in preparing for their journey. The experimenter was in charge of recording these verbalizations.

- The participants in group NO-PREPA did not prepare for the journey; they relied on directions provided in real-time during the journey.

The experimenter answered verbally to all questions, using a list of standardized responses. This list was built on the basis of the six main functions of navigation guiding, identified by Gaunet and Briffault (2005) :

- Localization. -

- Orientation. -

- Crossing. -

- Progression. -

- Intersection. -

- Route ending. -
For instance, "You are in front the subway" For instance, "You turn right into Lyon Street" For instance, "You cross Daumesnil BD" For instance, "Walk forward" For instance, "You arrive at an intersection" For instance, "You stop" 
The data that were recorded during the preparation phase differed according to the group:

- For the group wiTHOUT HUM-AID, data consisted of the participants' verbalizations during their own information research;

- For the group WITH HUM-AID, data consisted of the participants' questions to the experimenter.

During the mobility phase, the participants could obtain information using the "on-demand information" method. As described in Bisseret, Sébillotte and Falzon (1991), the rationale of this method is to provide participants with information if, and only if, it is asked for. Thus, the experimenter will not give any information on its own initiative. This allows to identify the key information which is needed by a participant.

During mobility, participants used their usual aids (either dog or cane, or technological tools), as they were used to do in their daily life. If needed, participants could request more information from the experimenter. The experimenter constantly followed the participants along the journey, and recorded verbalizations, which were subsequently converted into written text.

\section{III.4.2. Pre- and post-activity interviews}

Before the experiment, each participant took part in a semi-structured interview, lasting 20 to 30 minutes. Interview questions were based on a questionnaire. The goal of the interview was to identify the participants' navigation habits, including both journey-preparation habits (e.g., the tools that were used by participants for preparing their journey together with the difficulties that they encountered while doing so), and navigation habits per se. The verbal corpuses were analyzed according to the scheme described below.

A second semi-structured interview, lasting 30 to 40 minutes, took place just after the experiment, so as to identify the constraints and the resources taken into consideration during the journey.

\section{III.5. Data ANAlysis}

\section{III.5.1. Fourney preparation and realization}

Phase. - Navigation was divided into two phases: PREPARATIOn and MOBILITY. The preparation phase is dedicated to the preparation of the itinerary, including some investigations on Web sites. For blind individuals, this phase often takes place in a familiar place, for example at home or at the office. The mobility phase is dedicated to the journey execution.

Segment. - A pedestrian itinerary can be divided into segments delimited by two points, at which the traveler must reorient herself/himself. 
The information gathered during the preparation phase or the mobility phase relates to such segments. For example, the following sentence corresponds to a sole segment: "Take Brossolette street and walk straight on for 30 meters, then turn onto the $1^{\text {st }}$ street on your right." A degree of anticipation is associated to each segment. For a particular individual, this degree of anticipation (denoted Tn in Table 2) corresponds to the number of segments between the point where he/she is actually located (T0) and the point for which he/she is seeking information (see Figure 1 and Table 2.). Five degrees of anticipation were identified, as illustrated in Table 2.

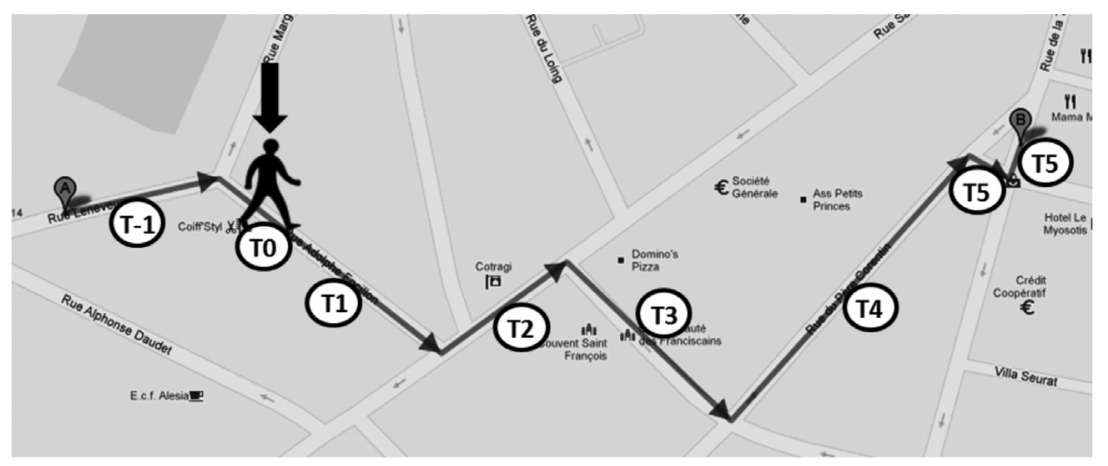

Figure. 1. Schematic example of itinerary segmentation. A new segment is created as soon as the pedestrian reorients herself. The number of reorientation between segment $\mathrm{T} 0$ and the location for which a question is asked defines the degree of anticipation of the request.

Figure. 1. Exemple de segmentation d'un itinéraire. Un nouveau segment est créé dès que le piéton se réoriente. Le nombre de réorientations entre le segment $T 0$ et le lieu à propos duquel la question a été posée determine le degree d'anticipation de la requête.

Information request. - Participants' verbalizations were recorded during the whole journey (preparation and mobility phase), and transcribed. This formed a set of data from which "information requests" (IRs) were extracted. An IR is the piece of information which is requested by a participant during the preparation phase and the mobility phase, either from the experimenter or from the navigation aids that were used. If different pieces of information were contained into one sentence, different IRs were identified. For the mobility phase, each question asked to the experimenter was counted as one IR, regardless of the group. For the preparation phase, each piece of information retrieved by participants of group 1 using web-based tools was counted as one IR. For the participants of group 2, each piece of information retrieved by asking "human aid" was counted as one IR.

Degree of anticipation. - In a second step, each IR was categorized according to the degree of anticipation to which it refers. The degree of anticipation is determined on the basis of the segment which is referred to 
in the IR. Coding the degree of anticipation in each IR was unequivocal and unambiguous and could thus be performed by a single coder.

TABLE 2. Categories of information requests (IRs), according to their associated degree of anticipation. The degree of anticipation corresponds to the number of reorientations needed between the participant's current location and the location corresponding to the question.

TABLEAU 2.Catégories de requêtes d'information (IRs), définies en fonction du degré d'anticipation associé. Le degré d'anticipation correspond au nombre de réorientations nécessaires entre la position du participant et le lieu vise par la requête d'information.

\begin{tabular}{|c|c|c|c|}
\hline $\begin{array}{l}\text { Segment } \\
\text { number }\end{array}$ & $\begin{array}{c}\text { Degree of } \\
\text { anticipation }\end{array}$ & $\begin{array}{c}\text { Information-request (IR) } \\
\text { categories }\end{array}$ & $\begin{array}{c}\text { Example of simultaneous } \\
\text { verbalization }\end{array}$ \\
\hline $\mathrm{T}-1$ & - 1 segment & $\begin{array}{l}\text { IR in relation to the pre- } \\
\text { ceding segment }\end{array}$ & $\begin{array}{l}\text { Did we went through the } \\
\text { big square? }\end{array}$ \\
\hline T0 & $\begin{array}{l}\text { Current } \\
\text { segment }\end{array}$ & $\begin{array}{l}\text { IR for the current } \\
\text { localization }\end{array}$ & $\begin{array}{l}\text { Where are we right now? } \\
\text { What street are we in? }\end{array}$ \\
\hline $\mathrm{T} 1$ & 1 segment & $\begin{array}{l}\text { IR taking into account the } \\
\text { next segment }\end{array}$ & $\begin{array}{l}\text { In which direction should } \\
\text { we leave? }\end{array}$ \\
\hline $\mathrm{T} 2$ & 2 segments & $\begin{array}{l}\text { IR taking into account the } \\
\text { next } 2 \text { segments }\end{array}$ & $\begin{array}{l}\text { When in Gerbert street, on } \\
\text { which side should I turn? }\end{array}$ \\
\hline T3 & 3 segments & $\begin{array}{l}\text { IR taking into account the } \\
\text { next } 3 \text { segments }\end{array}$ & As above \\
\hline $\mathrm{T} 4$ & 4 segments & $\begin{array}{l}\text { IR taking into account the } \\
\text { next } 4 \text { segments }\end{array}$ & As above \\
\hline T5 & $>4$ segments & $\begin{array}{l}\text { IR related to more than } \\
4 \text { segments in advance and } \\
\text { to the global planning of } \\
\text { the journey (overall view of } \\
\text { the journey, as opposed to } \\
\text { detailed instructions). }\end{array}$ & $\begin{array}{l}\text { Is the destination still far } \\
\text { away? } \\
\text { I have to take how many } \\
\text { more streets to get there? }\end{array}$ \\
\hline
\end{tabular}

\section{III.5.2. Pre-and post-activity interviews}

The semi-structured interviews were transcribed. The resulting corpus was subjected to protocol analysis. Verbal reports were segmented into semantic units that were identified according to a coding scheme. The coding scheme reflects the various components of knowledge. A semantic unit usually corresponds to a sentence. When a given sentence accounts for several distinct types of knowledge, it is segmented into several semantic units. 
Considering the aim of the study, this coding scheme was made of seven categories: Motive; Heuristic; Goal; Procedure; Prerequisite; Internal Resource or Constraint; External resource or Constraint. These coding scheme categories are described and illustrated in Table 3. The categories are mutually exclusive.

For example, we considered that the following sentence accounts for the use of a knowledge defined as an EXTERNAL CONSTRAINT : "What bothers me the most is the noise, street traffic and people who do not walk carefully." By contrast, the following sentence describes a HEURISTIC: "People on the street are not always reliable, thus, I like to ask the same information to several persons", and it was used by all six participants.

The participants' use of each semantic-unit category was tallied. Depending on which group he/she belongs to, one participant uses and articulates these knowledge components differently from the others. These various combinations form what we call strategies. Our aim was to bring into light these strategies and compare them.

TABLE 3 .Coding scheme used for protocol analysis.

TABLEaU 3. Schème de codage utilisé pour l'analyse de protocole.

\begin{tabular}{|c|c|c|}
\hline $\begin{array}{l}\text { Semantic } \\
\text { unit }\end{array}$ & Definition & Example \\
\hline Motive & $\begin{array}{l}\text { Rational or emotional reason that } \\
\text { prompts an activity }\end{array}$ & $\begin{array}{l}\text { "I like to perform a physical acti- } \\
\text { vity and to discover new places" }\end{array}$ \\
\hline Heuristic & $\begin{array}{l}\text { Rule used to organize the activity, } \\
\text { that promotes a favorable outcome, } \\
\text { but however does not necessarily } \\
\text { guarantee a successful outcome }\end{array}$ & $\begin{array}{l}\text { "People on the street are not } \\
\text { always reliable, thus, I like to } \\
\text { ask the same information to } \\
\text { several persons." }\end{array}$ \\
\hline GoAL & $\begin{array}{l}\text { What the individual seeks to achieve } \\
\text { with the activity }\end{array}$ & Go from one place to another \\
\hline Procedure & $\begin{array}{l}\text { The elaboration of an action plan, } \\
\text { including sub-goals }\end{array}$ & $\begin{array}{l}\text { "I will enter, on Google Map, } \\
\text { first, the starting point, then, the } \\
\text { destination point" }\end{array}$ \\
\hline PRerequisite & $\begin{array}{l}\text { Conditions that are required for the } \\
\text { implementation of the procedure }\end{array}$ & $\begin{array}{l}\text { "If I can access the internet, I } \\
\text { will look up the itinerary" }\end{array}$ \\
\hline $\begin{array}{l}\text { INTERNAL } \\
\text { RESOURCE OR } \\
\text { CONSTRAINT }\end{array}$ & $\begin{array}{l}\text { Knowledge that enables/limits the } \\
\text { goal completion }\end{array}$ & $\begin{array}{l}\text { "When I am tired, I am less } \\
\text { focused and attentive" }\end{array}$ \\
\hline $\begin{array}{l}\text { EXTERNAL } \\
\text { RESOURCE OR } \\
\text { CONSTRAINT }\end{array}$ & $\begin{array}{l}\text { Characteristic of the environment } \\
\text { (e.g., urban infrastructure, density } \\
\text { of the population or traffic), of the } \\
\text { technological aids (e.g. GPS), or of } \\
\text { the temporal conditions (e.g. bus } \\
\text { timetable) which enables/limits the } \\
\text { goal completion }\end{array}$ & $\begin{array}{l}\text { "What bothers me the most } \\
\text { is the noise, street traffic, } \\
\text { people who do not walk } \\
\text { carefully" }\end{array}$ \\
\hline
\end{tabular}




\section{WHAT INFORMATION DO BLIND INDIVIDUALS NEED TO COMPLETE AN UNKNOWN ITINERARY?}

\section{IV.1. OVERALL PERFORMANCE}

In this section, we focus on overall navigation performance. The recorded data are the time and the number of IRs that were needed to complete each phase.

For each group, we counted and averaged the numbers of IRs made during the course of the exercise. IRs made during the PREPARATION phase were treated separately from the IRs made during the MOBILITY phase. In addition, we compared these numbers with the average duration of these two phases, separately for each group. The results are shown in Figure 2.

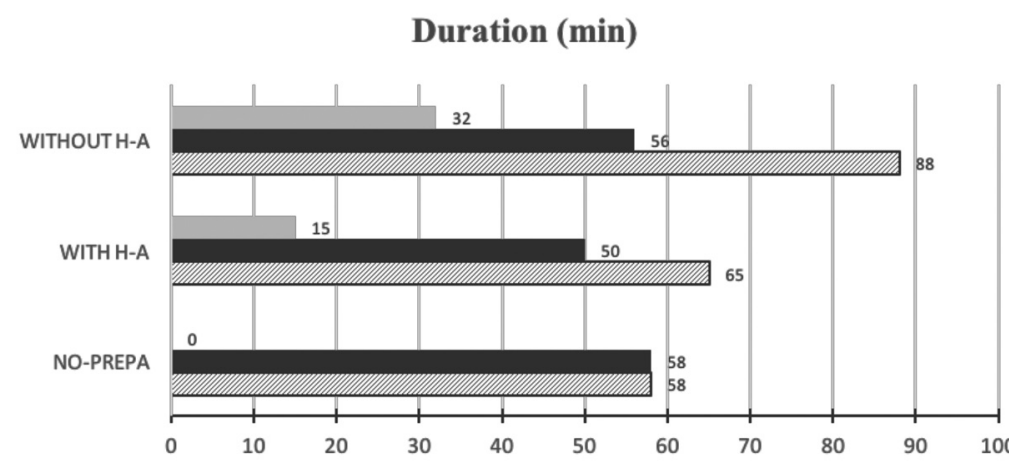

Number of information requests (IRs)

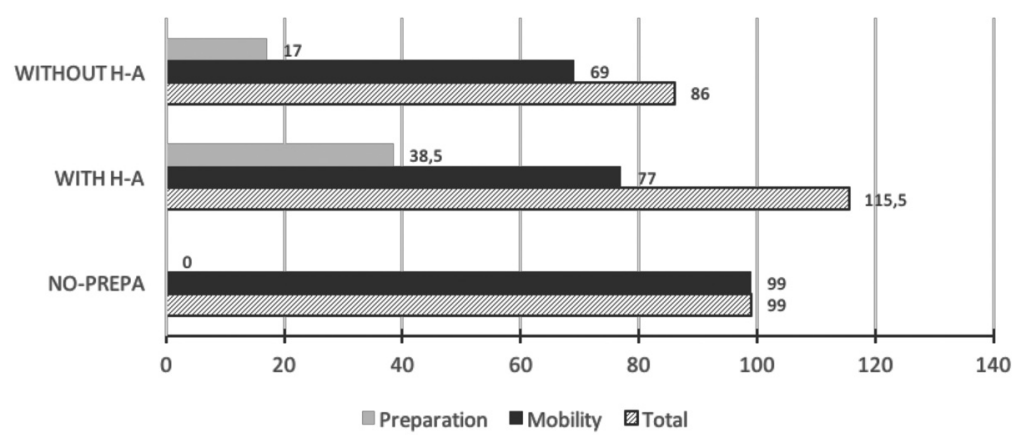

Figure 2. Average duration (in minutes) of the preparation and mobility phases for the three groups, and average number of information requests (IRs).

Figure 2.Durée moyenne (en minutes) des phases de préparation et de mobilité pour les trois groupes et nombre moyen de requêtes d'information (IRs).

PREPARATION phase. - The average number of IRs was approximately two times larger for group $2(M=38.5 ; S D=23.3)$ than for group 1 $(\mathrm{M}=17 ; \mathrm{SD}=0)$. The average duration in minutes of the PREPARATION phase 
was approximately two times longer for group $1(M=32 ; S D=2.8)$ than for group $2(M=15 ; D=4.2)$. Thus, for group 1 , approximately one third $(36.3 \%)$ of the total activity duration was spent preparing for the journey, whereas for group 2, only a quarter of the total activity duration (23\%) was devoted to preparation. To obtain a quantitative summary of performance within each group, we computed the average number of IRs per minute (number of IRs/duration). The result was equal to 0.53 (17/32) for group 1, and to $2.57(38.5 / 15)$ for group 2 .

One possible interpretation for such a difference is as follows. The participants in group 1, who were used to preparing for pedestrian journeys on their own using web-based resources, had access to precise information (e.g., exact distances and estimated durations for the different segments, and street names). However, they had access to a relatively small number of such pieces of information, because most of the information provided on Internet sites is not accessible to blind users. For example, most sites provide a visual map, but they lack a vocal synthesis system for describing the map to visually impaired users. The situation was quite different for the participants of group 2. In preparing for the journey, these participants benefited from a human assistance, capable of providing detailed verbal explanations concerning various aspects of the map. Thus, the participants in this group could obtain detailed information, including street names and numbers, and descriptions of street crossings. This may explain why better performance was observed for group 2 than for group 1: the participants in the former group could obtain all or most of the information needed to prepare for their journey in a relatively short time period.

MOBILITY phase. - For the MOBILITY phase, the average number of IRs was higher for group $3(M=99 ; \mathrm{SD}=18.4)$ than for groups 1 and 2. For group $1,80.3 \%(69 / 86)$ of the IRs were made during the MOBILITY phase, versus $66.7 \%(77 / 115.5)$ for group 2 . The overall duration of the journey was similar for the three groups, being comprised between $50(\mathrm{SD}=9.9)$ and $58(\mathrm{SD}=18.4)$ minutes.

Performance during the MOBILITY phase was quantified for each group by dividing the number of IRs made during the journey by the overall journey duration; low scores thus indicate high performance. The score is equal to $1.23(69 / 56)$ for group 1 , to $1.54(77 / 50)$ for group 2 , and to $1.71(99 / 58)$ for group 3. This tends to indicate slightly better performance for group 1 (whose participants prepared for the journey without any human assistance) followed by group 2 (preparation alone) and then, group 3 (no preparation).

Thus, the duration of the MOBILITY phase is similar for the three groups but the number of IRs is higher for group 3. A possible interpretation of this result is that the PREPARATION phase allowed the participants of groups 1 and 2 to form a global understanding of the journey to perform, thereby increasing their autonomy.

Global navigation activity [PREPARATION + MOBILITY]. - In this section, we consider overall performance, including both phases (PREPARATION and MOBILITY). The number of IRs appears close for the three groups: 86 for group $1(\mathrm{SD}=1.4) ; 115.5$ for group $2(\mathrm{SD}=19.1)$; and 99 for group $3(\mathrm{SD}=18.4)$. 
The overall duration (in minutes) of the activity was longer for group 1 ( $M=88$; $\mathrm{SD}=15.6$ ) than for the other two groups (for group $2, M=65, \mathrm{SD}=14.1$; for group 3, $M=58, S D=18.4$ ). When these numbers were converted into performance scores as described above (number of IRs/duration), group 1 was found to have the lowest performance with 0.97 (86/88). Groups 2 and 3 were in a tie: group 2 obtained 1.78 (115.5/65); group 3 obtained $1.71(99 / 58)$.

Thus, group 2 , in which the participants prepared for the journey, obtained the same performance as group 3, in which the participants did not prepare for the trip. These results suggest that using navigation aids during the preparation phase, which can take a considerable amount of time for acquiring information, does not result in improving the time to complete the journey nor navigation performance.

However, it is important to note that these conclusions are based on a relatively narrow definition of the notion of "navigation performance." This performance was quantified by dividing the number of information requests (made by the participant before or during the journey) by the duration of the journey. Other performance criteria, such as the participant's degree of autonomy and stress management, should also be taken into account. In this context, it is worth pointing out that groups 1 and 2 were probably better equipped than group 3, as indicated by the fact that the participants of these groups made a relatively small number of IRs while not needing more time to complete their journey.

\section{IV.2. Degree of ANTICIPATION}

In this section, we consider the degree of anticipation for each IR during the PREPARATION and MOBILITY phases. To this aim, we computed the percentage of IRs for each category (as described in Table 2) and each group. The results are presented in Figure 3.

PREPARATION PHASE. - During this phase, the highest percentage of IRs measured in groups 1 and 2 corresponds to the category T5. The IRs in this category relate to a global, wide and long-term (as opposed to local, piece-wise, and short-term) mental representation of the itinerary. This observation suggests that the participants in these two groups were engaged in intense planning. This appears to be the case, especially, for the participants in group 2 (who benefited from human assistance): they devoted approximately $1 / 4$ of their IRs to building a global, long-term representation of the itinerary. Note that participants of the group 3 did not plan their journey and thus did not have any IRs measured during this phase.

MOBILITY PHASE. - During this phase, the most frequent IRs are those concerning the next first segment (T1): for all three groups, more than a third of IRs belonged to this category. IRs concerning the participants' current location (T0) are also quite frequent, especially for groups 1 et 3, for which this IR category corresponds approximately to $1 / 4$ of the IRs' total number. Together, these two categories correspond approximately to $2 / 3$ of the IRs' total number. The remaining IRs are related to future segments of the journey (T2, T3, T4, and T5). Groups 1 and 2 differed markedly 
from group 3 in their use of these IR categories. The former two groups made moderate use of IRs in the T2 category, very little use of IRs in the $\mathrm{T} 3$ and T4 categories, and almost no use of IRs in the T5 category. By contrast, participants of group 3 made a substantially larger percentage of IRs concerning segments T2 and T3. Moreover, the participants of this group tried to anticipate their journey up to the $\mathrm{T} 4$ and $\mathrm{T} 5$ segments.

These results may be indicative of two different "cognitive styles" in the formation of spatial representations: some participants (group 3) favor "local" representations of the environment, while others (groups 1 and 2) favor "global" representations of the navigation space.
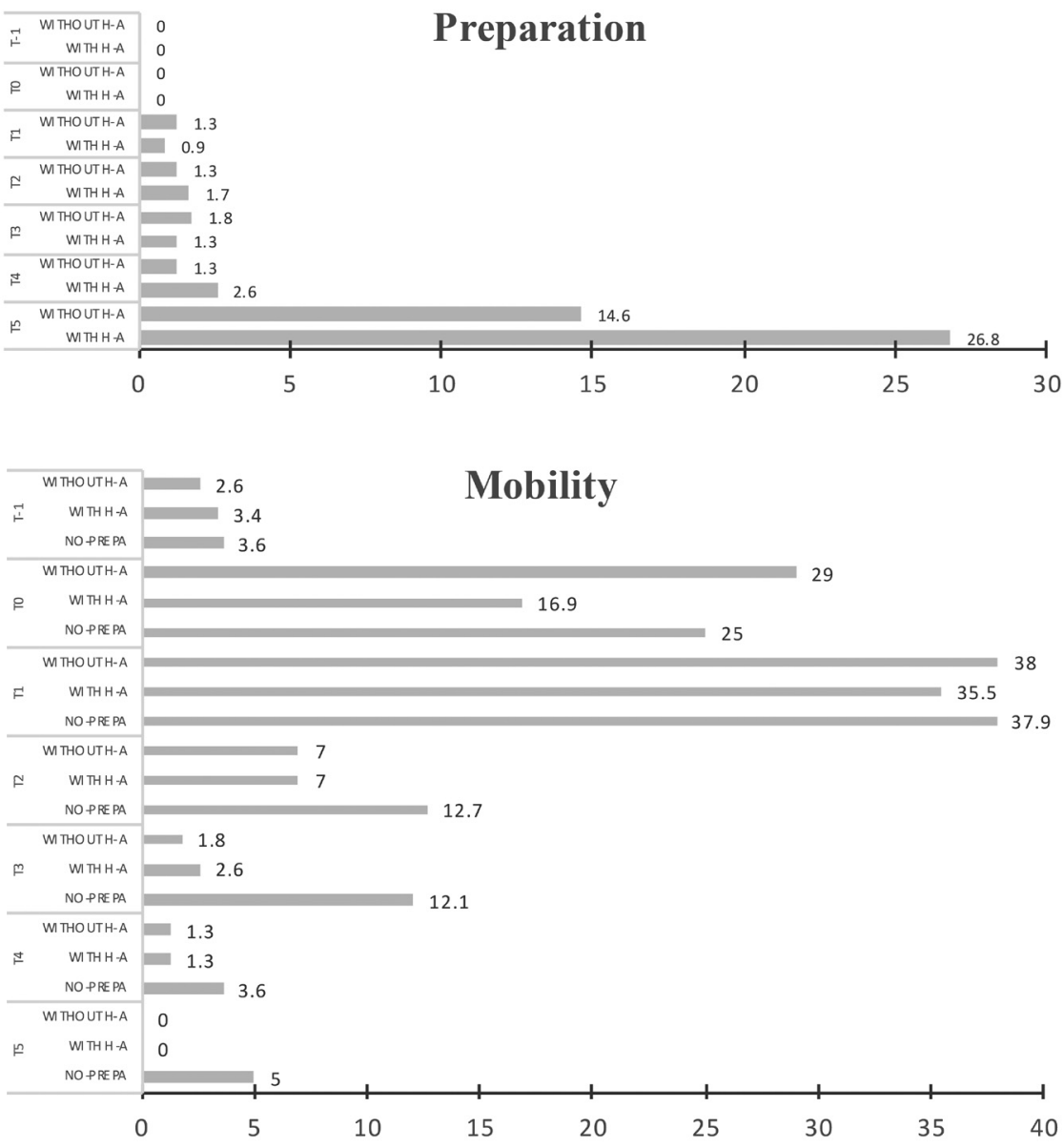

Figure 3. Mean percentage of IR category (from T-1 to T5), as a function of the navigation phase for the different groups.

Figure 3.Pour chaque groupe, proportion moyenne des catégories d'IRs (de T-1 à T5), en fonction de la phase de navigation. 


\section{WHAT STRATEGIES DO BLIND INDIVIDUALS USE WHEN WALKING IN AN UNKNOWN ENVIRONMENT?}

\section{V.1. OBJECTIVE AND METHOD}

The second part of our study aims at shedding light on the diversity of strategies used by blind individuals during a pedestrian journey in an unknown environment. Considering that these strategies depend on the expert knowledge acquired during their daily navigation activities, we sought to identify the nature and content of this knowledge (external constraints, internal resources, procedures and heuristics), and to determine how it is involved in the formation of navigation strategies. We hypothesized that these strategies would differ depending on how participants organize their journey: on their own, with the help of another individual, or without preparation.

The results presented in the subsequent sections are extracted from the analysis of the participants' verbalizations, as described in section III.5.B. These verbal data reflect the participants' knowledge about their expertise in navigation. These data were categorized according to three classes of semantic units: RESOURCES, CONSTRAINTS, HEURISTICS. In our analysis, we included only the semantic units that were used by a least 4 out of the 6 participants. Subsequently, the ways in which different elements of this knowledge are articulated to form STRATEGIES are described.

\section{V.2. EXTERNAL CONSTRAINTS AND RESOURCES INFLUENCING NAVIGATION}

The EXTERnAl RESOURCES and EXTERNAL CONSTRAINTS that were unanimously mentioned by the participants are reported in Table 4 .

It can be seen that other pedestrians (or bystanders) appear as an essential EXTERNAL RESOURCE: all participants said that it is easier for them to find help in environments in which many other pedestrians (or bystanders) are present, such as a large city or a popular neighborhood with many shops. Moreover, the presence of other pedestrians is reassuring for blind individuals, even when they do not need to obtain information. Some other EXTERNAL RESOURCES were also mentioned, although not by all participants, as for instance having the opportunity to use Web sites for public transportation. Other EXTERNAL RESOURCES, which were accessible to all participants, included public transportation and metro maps in Braille. During the interviews, the participants indicated that the unreliability of navigation tools (e.g., GPS) and the lack of information concerning available offers stifled their adoption of new technologies.

The EXTERNAL CONSTRAINTS are not merely a "mirror image" of the resources. We report in Table 4 those that were unanimously mentioned by the participants.

It can be seen that the participants were unanimous in indicating that other pedestrians are one of the main EXTERNAL CONSTRAINTS because they sometimes provide incorrect information, speak a foreign language, or 
simply, refuse to help. Other pedestrians are also the main element of the "time" CONSTRAINT because, depending on the time at which the journey takes place, one is more or less likely to meet other pedestrians. The participants also underscored the unreliability of GPS devices, and the fact that these devices do not provide all of the information needed to complete the journey (e.g., directions upon an existing metro station, confirmation that the user arrived at the correct destination). EXTERNAL CONSTRAINTS refer, either to a "waste of time," or to the necessity of arriving at the destination at a specific time. For instance, when the time allotted for the journey is short, the preparation of the journey must be thorough, so that the individual can rapidly adapt to unexpected situations.

TABLE 4. External resources and external constraints unanimously mentioned by the participants during the individual interviews.

TABLEAU 4. Ressources externes et contraintes externes qui ont été unanimement mentionnées par les participants au cours des entretiens individuels.

\author{
EXTERNAL RESOURCES (environmental, assistance, temporal) \\ Other pedestrians or bystanders \\ Parisian neighborhood with many shops and people \\ White cane /guide-dog \\ Public transportation \\ Metro map in Braille
}

\begin{abstract}
EXTERNAL CONSTRAINTS (environmental, assistance, temporal)
Environment with no other pedestrians (suburb/small town/ rural environment)

Other pedestrians are not reliable (they do not always answer questions or they provide incorrect information)

To arrive on time (have a precise idea of the duration of the journey)

Bad or unreliable GPS reception

GPS does not provide all of the necessary information (what direction to take when getting out of a metro station, confirmation that this is the correct place)
\end{abstract}

\title{
V.3. CONSTRAINTS AND INTERNAL RESOURCES INFLUENCING NAVIGATION
}

A single INTERNAL RESOURCE is accessible to all six participants: the knowledge acquired during a previous execution of the same journeys. Having a mental representation of an itinerary is, therefore, an important advantage.

Regarding INTERNAL CONSTRAINTS, stress and anxiety were only observed (4/6) for groups 1 and 2. Individual interviews with the participants allowed us to understand that preparing for the journey was the way in which these individuals managed their anxiety and their stress during the journey. The participants from group 3, who did not prepare for the journey, were not subject to anxiety caused by the need to make a journey without knowing the itinerary in advance because, according to them, "they would always find someone to whom they could ask for directions." 


\section{V.4. HEURISTICS}

The HEURISTICS used by blind individuals to support the elaboration of navigation strategies are summarized in Table 6 . The results, presented in Table 5, reveal that some HEURISTICS were used by all participants, while others depended strongly on which group the participant belonged to and, therefore, on the way in which participants prepared for their journey.

Regarding the common HEURISTICS, they relate to public transportation, and they can be summarized as follows:

- take public transportation to arrive as close as possible to the destination, and thus reduce walking distance;

- prepare for the public-transportation journey in advance is mandatory (even for those blind individuals who do not prepare their pedestrian itinerary);

- when lost, ask other pedestrians for directions;

- one must know that the information provided by other pedestrians is not always reliable.

Other HEURISTICS, which were used specifically by participants who prepared for their itinerary (groups 1 and 2), were as follows:

- the participants in group 1 prepared for their journey on their own in order to be as autonomous as possible, both, in the preparation phase and in the mobility phase. For these individuals, the preparation phase was important in order to avoid having to rely on other pedestrians - who might not be there;

- the participants in groups 1 and 2 prepared for their journey one to eight days in advance, so that they would have enough time to memorize the directions.

The analysis of the CONSTRAINTS, RESOURCES, and HEURISTICS revealed that the goal of preparation is not solely to gather information for the journey, but also, to more efficiently utilize the gathered information.

TABLE.5. Heuristics identified by the participants for the PREPARATION and MOBILITY phases.

TABlEaU.5.Heuristiques identifiées par les participants pour les phases de PRÉPARATION et de MOBILITÉ.

\begin{tabular}{|l|c|}
\hline HEURISTICS pertaining to the PREPARATION phase & Total \\
\hline - Preparing for a journey via public transportation is mandatory & $6 / 6$ \\
\hline - Use public transportation to arrive as close as possible to the destination & $5 / 6$ \\
\hline - Preparing for a journey alleviates stress & $4 / 6$ \\
\hline $\begin{array}{l}\text { - Preparing an itinerary in advance allows one to form a good representation } \\
\text { of the route prior to the start of the journey }\end{array}$ & $4 / 6$ \\
\hline $\begin{array}{l}\text { - Long instructions must be recorded in order to ensure that they are not } \\
\text { forgotten during the journey }\end{array}$ & $4 / 6$ \\
\hline $\begin{array}{l}\text { - Know the names of streets is useful to locate one's position during the } \\
\text { journey (by asking other pedestrians or using a GPS device) }\end{array}$ & $4 / 6$ \\
\hline $\begin{array}{l}\text { - Form a cartographic mental representation of the itinerary makes it possible } \\
\text { to find back one's way when lost }\end{array}$ & $4 / 6$ \\
\hline
\end{tabular}




\begin{tabular}{|l|c|}
\hline HEURISTICS pertaining to the MOBILITY phase & Total \\
\hline - When lost, ask pedestrians for directions & $6 / 6$ \\
\hline $\begin{array}{l}\text { - The information provided by other pedestrians is reassuring but not always } \\
\text { reliable }\end{array}$ & $6 / 6$ \\
\hline $\begin{array}{l}\text { - Although it may take time, one always ends up finding another pedestrian } \\
\text { whom to ask for directions }\end{array}$ & $6 / 6$ \\
\hline - Always remain on the side of the walkway where one must turn next & $5 / 6$ \\
\hline - GPS is an additional element of reassurance, but is not reliable & $4 / 6$ \\
\hline
\end{tabular}

\section{V.5. SCHEMATIC REPRESENTATIONS OF NAVIGATION ACTIVITIES}

In this section, we describe the navigation strategies adopted by each group of participants. These strategies are outlined on the basis of the participants' verbalizations analysis (as described in the preceding section). They are illustrated in the form of decision trees, which combine the heuristics and the resources, as presented in Figures 4 to 6 . The aim of these decision trees is to facilitate comparisons of strategies across the different groups and to highlight general trends.

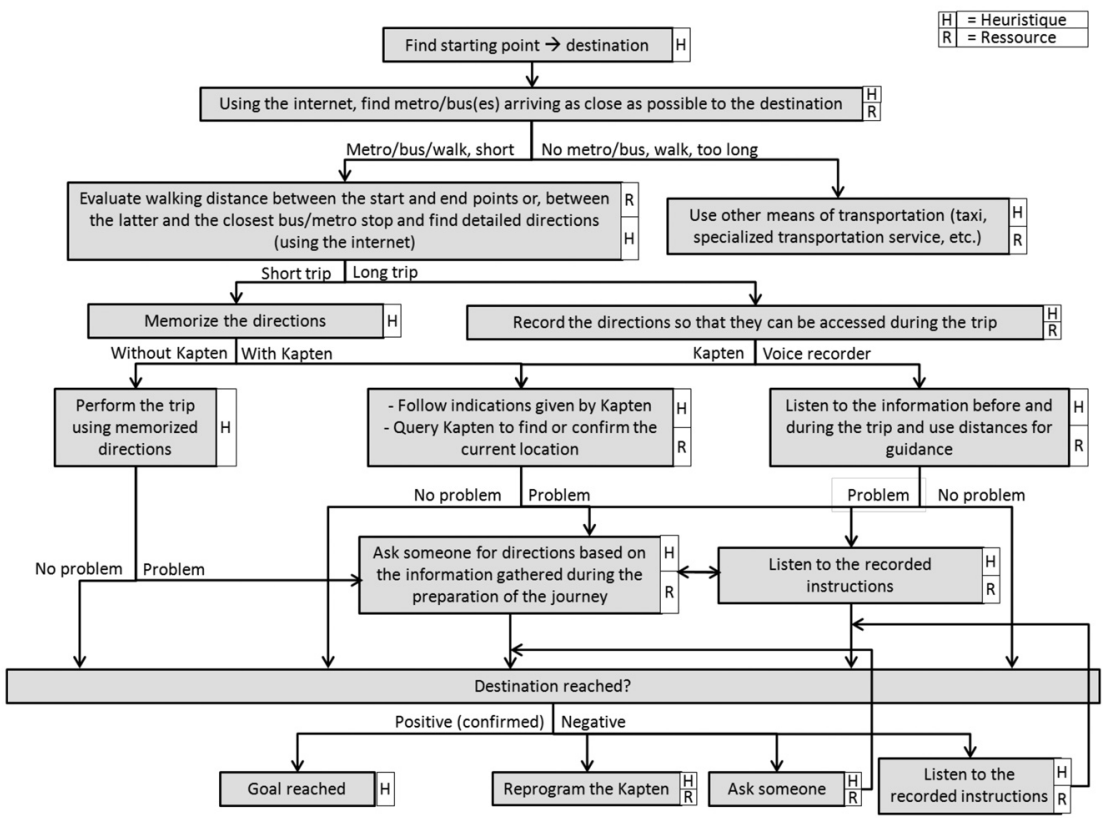

Figure 4. Decision treeof group 1. Each box is called a "navigation component", the content of whichis identified in terms of heuristics $(\mathrm{H})$ and /or resources (R).

Figure 4. Arbre de decision du groupe 1. Chaque rectangle est appelé "élément de navigation", dont le contenu peut être décrit en termes d'heuristiques $(H)$

et / ou de ressources (R). 


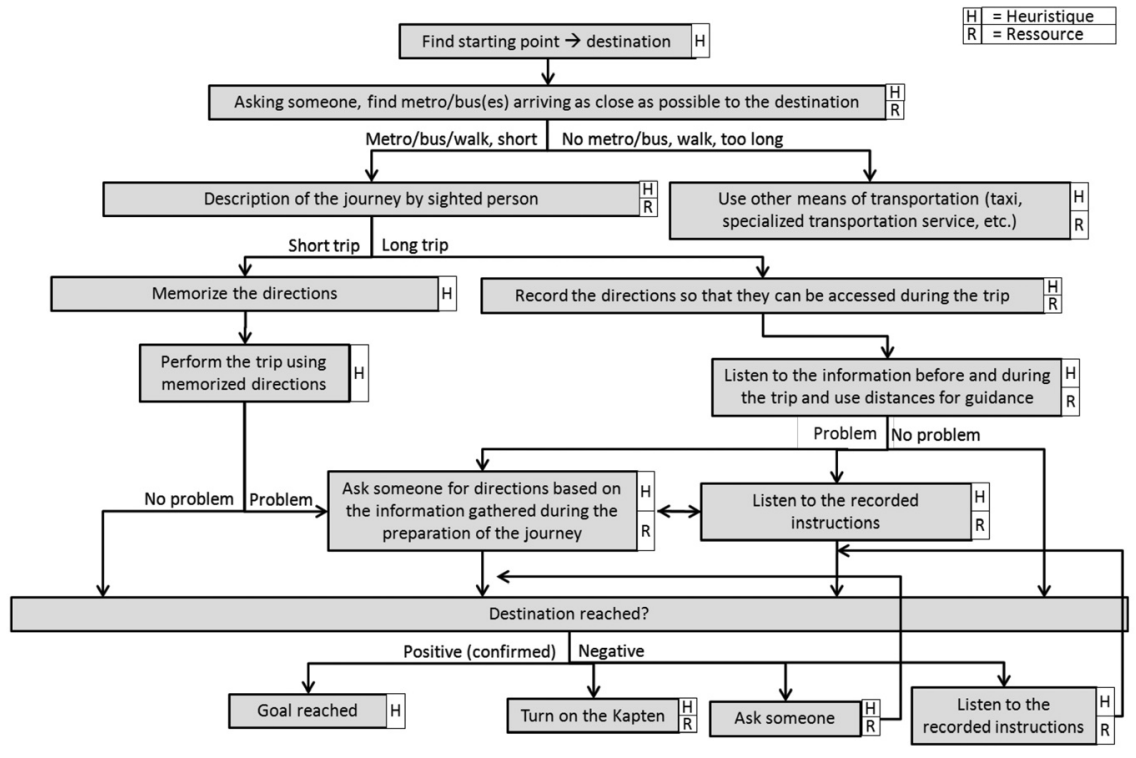

Figure 5. Decision tree of group 2. Each box is called a "navigation component", the content of which is identified in terms of heuristics $(\mathrm{H})$ and /or resources (R).

Figure 5. Arbre de decision du groupe 2. Chaque rectangleest appelé "élément de navigation", dont le contenu peut être décrit en termes d'heuristiques $(H)$ et / ou de ressources (R).

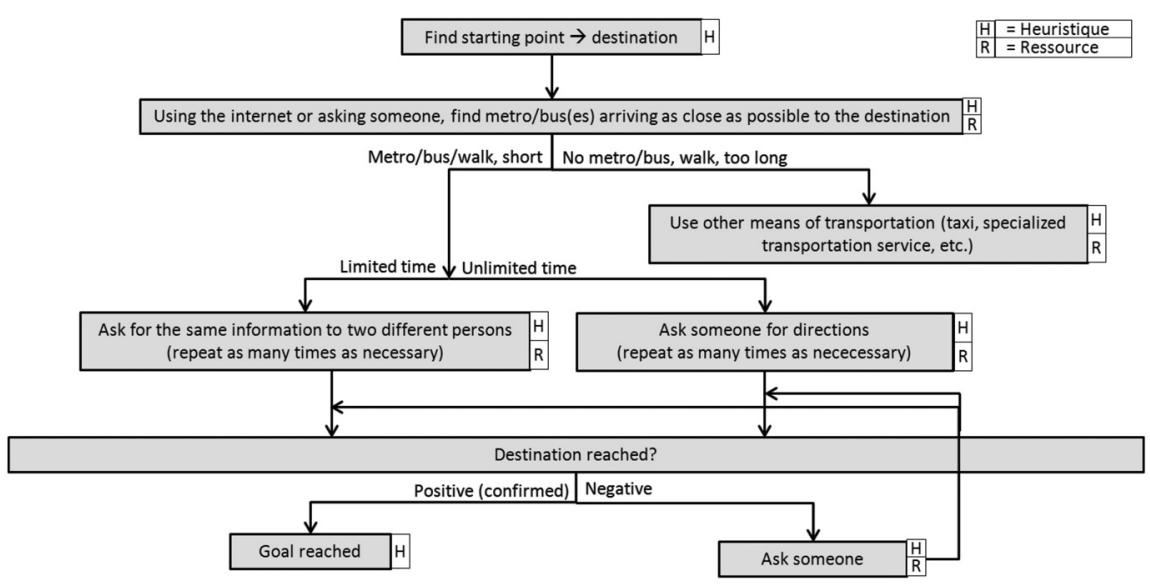

Figure 6. Decision tree of group 3. Each box is called a "navigation component", the content of which is identified in terms of heuristics $(H)$ and /or resources $(\mathrm{R})$.

Figure 6. Arbre de decision du groupe 3. Chaque rectangle est appelé "élément de navigation", dont le contenu peut être décrit en termes d'heuristiques $(H)$ et / ou de ressources $(R)$. 
The analysis revealed the following similarities and differences between the navigation strategies of the different groups, as shown in Table 6 and Table 7:

TABLE 6. Number of components and number of levels of refinement forming the navigation strategy, as a function of the group (Group 1: preparation without human assistance, Group 2: preparation with human assistance, Group 3: no preparation).

TABLEAU 6. Nombre de composants et nombre de niveaux de raffinement qui composent la stratégie de navigation, en fonction du groupe (Groupe 1:préparation sans assistance humaine, Groupe 2: préparation avec assistance humaine, Group 3: sans préparation).

\begin{tabular}{lccc}
\cline { 2 - 4 } & Group 1 & Group 2 & Group 3 \\
\hline Number of levels & 8 & 8 & 6 \\
\hline Number of components & 16 & 15 & 8 \\
\hline
\end{tabular}

TABLE 7. Heuristics and resources identified through the analysis of participants' verbalizations, as a function of the group.

TABleau 7. Heuristiques and ressources identifiées par l'analyse des verbalisations des participants, en fonction du groupe.

\begin{tabular}{lccc}
\cline { 2 - 4 } & Group 1 & Group 2 & Group 3 \\
\hline Heuristic & 15 & 14 & 7 \\
\hline Resource & 6 & 7 & 5 \\
\hline
\end{tabular}

The strategies developed by the participants in group 1 and group 2 were considerably more sophisticated than the strategies of the participants in group 3, in terms of complexity as well as in terms of knowledge content:

- the decision trees of groups 1 and 2 involved twice as many components as that of group 3 (Table 7);

- the depth of the decision tree is less for group 3 than for the other groups, though not markedly (Table 7);

- the number of heuristics for groups 1 and 2 was the double than for group 3 (Table 8);

- the number of resources was approximately equal for the different groups: about three fourths of the resources were related to navigation aids (either tools such as the internet or a GPS, or human resources, such as other pedestrians);

- while group 3 relied almost exclusively on other pedestrians, groups 1 and 2 used a wider range of resources. 
We suggest that the strategies of groups 1 and 2, which involved a larger number of heuristics and a wider array of resources, were based on cognitive representations of the urban space stored in long-term memory. In addition, one might assume that the participants in groups 1 and 2 become more autonomous than those in group 3, regarding navigation tasks.

\section{DISCUSSION AND RECOMMENDATIONS FOR THE DESIGN OF NAVIGATION AIDS}

The exploratory study reported here had two main aims. The first one was to investigate how, and according to what temporal sequence, blind individuals gather information when preparing for an unfamiliar itinerary through a real, urban environment. The second aim was to investigate blind individuals' navigation strategies. We examined the determinants of the navigation activity in order to infer the participants' strategies. The results revealed, accordingly to our hypothesis, that the way in which blind individuals prepare for a journey - without human assistance, with human assistance, or no preparation - influences how they gather information before, and during, the journey. Based on the results of this study, we draw some recommendations concerning the design of navigation aids for blind pedestrians.

\section{VI.1. EVALUATING THE PERFORMANCE OF BLIND PEDESTRIANS NAVIGATION}

When evaluating blind individuals' navigation performance, it is typical to consider the distance traveled and the duration of the journey. The results of the current study indicate that other factors should be taken into account: the level of stress and anxiety experienced by the individual before and during the journey, and the extent to which the individual manages to cope with them, the ability to form an operational mental representation of the itinerary prior to the journey, and the individual's degree of autonomy. These factors depend on people's personality, which has an influence on the strategies that are used. These strategies thus have to be identified and taken into account when designing a new navigation aid, so that it is well accepted by users (Arnold et al., 2017-a).

\section{VI.2. IMPORTANCE OF THE TEMPORAL CONSTRAINT ON NAVIGATION}

The results of this study first revealed the importance of the temporal constraint (i.e., the time allocated to the different phases of the journey) on blind people's navigation. Although this constraint has been considered in some studies investigating how sighted people plan their automobile activities (Chalmé, Visser, \& Denis, 2004; Ho \& Spence, 2008), it has received little attention in the context of pedestrian-navigation. In our study, although this temporal constraint was observed in all participants, it manifested itself in different ways: while some participants paid special 
attention to the PREPARATION phase in order to save time for later (i.e., optimization of the MOBILITY phase), other participants skipped the PREPARATION phase to save time now. One way to take into account the temporal constraint in navigation aids for blind users is to adapt the information that is provided to the user depending on the time allotted for the journey and its preparation.

In accordance with previous work (Gaunet \& Briffault, 2005), the results of the current study suggest that important information, which should be provided to blind users in order to favour an efficient and effective preparation of a pedestrian journey, include: the estimated duration of the journey, the overall direction, the number of streets that will be used or crossed, and the length of each segment. Users who are prepared for their journey and have these various pieces of information at hand will need fewer indications during the journey. Moreover, since they will already have a global mental representation of the journey, these indications could be limited to the current segment and the next segment. One may hypothesize that the mental representations of these participants are operative (Ochanine, 1978), ie the representations allow participants to achieve their goal and reach their destination efficiently. Users who have not prepared for the journey will need to obtain more information during the journey, in particular, information that allows them to anticipate on subsequent segments.

\section{VI.3. TAKING INTO ACCOUNT STRESS MANAGEMENT}

The results of this study emphasize the need to take into consideration the anxiety experienced by blind pedestrians during the preparation and execution of a journey involving an unfamiliar itinerary, when designing navigation-aid devices. This psychological constraint was underscored in previous studies (e.g., Nelson et al., 2006). We found that the two groups of participants who prepared for their journey found it comforting to have a mental representation of the itinerary prior to the journey.

Therefore, navigation aids should make easier for the user to relate pieces of information gathered during the journey to the preliminary representation of the itinerary. Providing users with detailed information concerning the itinerary allows them to form a clearer mental representation of the itinerary and to better anticipate difficulties. Such functionalities would help to lower the stress generated by the necessity to perform a journey in an unfamiliar environment.

\section{VI.4. FREEING BLIND USERS FROM THE NEED TO RELY ON OTHER PEDESTRIANS}

Several authors have emphasized the shortcomings and underuse of GPS devices for pedestrian navigation (Baudoin et al., 2005; Denham et al., 2004; Spérandio \& Uzan, 2004). Consistent with this, while all of the participants in the present study have mentioned GPS-based aids (in particular, the Kapten, which is currently the most accessible and wellknown device) as a potential resource, they also mentioned that, due to 
reliability issues, they rarely used it. This explains, in part, why blind individuals often rely critically on other pedestrians to manage anxiety when following an unfamiliar itinerary. This resource allows blind pedestrians who do not have navigation aids - or whose navigation aid does not work - to confirm that they are on the right track. The fact that all participants, regardless of whether or not they use navigation aids, mentioned other pedestrians as a key resource underscores the insufficiency of existing navigation aid devices. A device that would be more reliable than currently existing ones, and that would offer a more user-friendly interface, could allow blind pedestrians to free themselves from the need to rely on other pedestrians.

Our study also raises the question of the involvement of blind individuals in the design of assistive devices. Unlike other products for which the need is not clear a priori, blind individuals' expectations concerning these devices are high because they can greatly enhance their autonomy (Katz et al., 2012-a; 2012-b). As Bastien and Scapin (1993) pointed out, the characteristics of the users of a device change over time. Therefore, ideally, the device should be adaptive and adjustable, depending on the users' level of experience (Arnold et al, 2017-b). The increasing use of navigation aids by blind individuals will alter the habits of this population, and will lead to the emergence of new models of the navigation activity.

\section{VI.5. NAVIGATION AIDS AND SPATIAL MENTAL REPRESENTATIONS}

The involvement of disabled users in the design of assistive devices is necessary to ensure that these devices are well adapted to the target population (Katz et al., 2012-a; 2012-b). However, it can also play a key role in investigating the long-term impact of these devices. Too much reliance on a guiding system can lead their users to "passively" follow an itinerary, and to do not encode the spatial relationships that link different elements in a scene. To avoid that users of assistive devices become too dependent upon these devices, it is imperative to actively involve them in the design of the technology.

\section{CONCLUSION}

The results of our study underscore the key role of the preparation phase in the construction of mental representations of the itinerary, which allow the individual to anticipate subsequent segments. Our analyses of participants' verbalizations revealed the existence of common determinants of the activity, which were shared by all participants (the temporal constraint and the "other pedestrians" resource), and of other resources, which were specific to certain groups (such as anxiety).

Based on these results, we draw some recommendations concerning the provision of information to blind pedestrians. Moreover, the results underlined the importance of an in-depth analysis of the needs and strategies of 
blind individuals when designing a navigation-aid device that is likely to be widely adopted by the target population.

In this context, an important goal for future studies is to further investigate the influence of interindividual differences on navigation performance. The participants in our study described themselves as individuals who were not afraid of walking in the street, to take risks, and to make trips without assistance. It would be interesting to examine whether, and to what extent, navigation aids benefit individuals who are less confident in their ability to navigate on their own.

We conjecture that age differences are an important factor of navigation strategies. Visual impairments are more prevalent among the elderly, a population characterized by marked inter-individual differences in physical, intellectual, sensory, and cognitive abilities. Thus, the needs of the elderly with respect to assistive devices may differ among them. This is another reason for developing flexible devices, which can adapt to the needs and abilities of each individual user.

This work was supported by the French National Research Agency (project NAVIG ANR-08-TECS-011).

\section{REFERENCES}

Afonso, A., Blum, A., Katz, B. F. G., Tarroux, P., Borst, G., \& Denis, M. (2010). Structural properties of spatial representations in blind people: Scanning images constructed from haptic exploration or from locomotion in a 3-D audio virtual environment. Memory and Cognition, 38, 591-604.

Almeida, M.X., Martins, L.B., \& Lima, F.J. (2015). Analysis of wayfinding strategies of blind people using tactile maps. Proceedings of the 6th International Conference on Applied Human Factors and Ergonomics, AFHE 2015. Procedia Manufacturing, 3, 6020-6027.

Arnold, G. \& Auvray, M. (2017). The graphesthesia paradigm: drawing letters on the body to investigate the embodied nature of spatial perspective taking. I-Perception, 8, 1-5. doi: 10.1177/2041669517690163.

Arnold, G., Pesnot-Lerousseau, J., \& Auvray, M. (2017a). Individual differences in sensory substitution. Multisensory Research, 6, 579-600.

Arnold, G., Spence, C., \& Auvray, M. (2017b). A unity of the self or a multiplicity of locations? How the graphesthesia task sheds light on the role of spatial perspectives in bodily self-consciousness. Consciousness $\mathcal{E}$ Cognition, $56,100-114$.

Arnold, G., Spence, C., \& Auvray, M. (2016). Taking someone else's spatial perspective: Natural stance or effortful decentring? Cognition, 148, 27-33.

Avraamides, M. N., Galati, A., Pazzaglia, F., Meneghetti, C., \& Denis, M. (2013). Encoding and updating spatial information presented in narratives. Quarterly fournal of Experimental Psychology, 66, 642-670.

Bastien, C., \& Scapin, L. (1993). Ergonomic Criteria for the Evaluation of HumanComputer Interfaces. Technical report $\mathrm{n}^{\circ} 156$, Rocquencourt : INRIA.

Baudoin, G., Venard, O., Uzan, G., Rousseau, A., Benabou, Y., Paumier, A., \& Cesbron, J. (2005). The RAMPE Project: Interactive, Auditive Information System for the Mobility of Blind People in Public Transports. Proceedings of the $5^{\text {th }}$ International Conference on ITS Telecommunications, June 27-29, Brest, France, pp.169-176. 
Becchio, C., Del Giudice, M., Dal Monte, O., Latini-Corazzini, L., \& Pia, L. (2011). In your place: neuropsychological evidence for altercentric remapping in embodied perspective taking. Social cognitive and affective neuroscience, $8,165-170$.

Benetti, E \& Collignon, O (2014). Is there a future for sensory substitution outside academic Laboratories? Multisensory Research, 27, 271-291.

Bisseret. A., Sebillote. S., \& Falzon.P. (1991). Techniques pratiques pour l'étude des activités expertes [Practical techniques for the study of expert activities]. Toulouse : Octarès.

Cecílio, J., Duarte, K., \& Furtado, P. (2015). BlindeDroid: An Information Tracking System for Real-time Guiding of Blind People. Procedia Computer Science, 52, 113-120.

CERTU (2008). Déplacements des déficients visuels en milieu urbain Analyse des besoins en sécurité, localisation et orientation, et pistes d'évolution. Collection "Rapports d'étude ». Retrieved 25 February 2018 from http://reglementationsaccessibilite.blogs.apf.asso.fr/files/

Voirietechnique/déplacements \%20déficients \%20visuels \%2C\%20CERTU\% 2C\%202008.pdf

Chalmé, S., Visser, W., \& Denis, M. (2004). Cognitive effects of environmental knowledge on urban route planning strategies. In T. Rothengatter \& R. D. Huguenin (Eds.), Traffic and Transport Psychology. Theory and Application (p. 61-71). Amsterdam: Elsevier.

Denham, J., Leventhal, J., \& McComas, H. (2004). Getting from Point A to Point B: Review of two GPS systems. AccessWorld, 5(6). Retrieved January 13, 2012, from http://www. afb.org/ afbpress/pub.asp?DocID= aw0506toc.

Denis, M. (2018). Space and spatial cognition: A multidisciplinary perspective. Abingdon, UK: Routledge.

Denis, M. \& Zimmer, H. D. (1992). Analog properties of cognitive maps constructed from verbal descriptions. Psychological Research, 54, 286-298.

Deroy, O., Fasiello, I., Hayward, V., \& Auvray, M. (2016). Differentiated audiotactile correspondences in sighted and blind individuals. Fournal of Experimental Psychology: Human Perception and Performance, 42, 1204-1214.

Eardley, A.F., Edwards, G., Malouin, F., \& Kennedy, J. (2016). Allocentric Spatial Performance Higher in Early-Blind and Sighted Adults Than in Retinopathyof-Prematurity Adults. Perception, 45, 281-299.

Fougeyrollas, P. Cloutier, R., Bergeron, H., \& Côté, G. (1998). Classification québécoise : Processus de production du handicap [Quebec classification: processus of disability production]. RIPPH/SCCIDIH, 166 p., Quebec.

Gallay, M., Denis, M., \& Auvray, M. (2013). Navigation assistance for blind pedestrians: Guidelines for the design of devices and implications for spatial cognition. In T. Tenbrink, J. Wiener, \& C. Claramunt (Eds.), Representing space in cognition: Interrelations of behaviour, language, and formal models (pp. 244-267). Oxford: Oxford University Press.

Gaunet, F. \& Briffault, X. (2005). Exploring the Functional Specifications of a Localized Wayfinding Verbal Aid for Blind Pedestrians: Simple and Structured Urban Areas, Human-Computer Interaction, 20(3), 267-314.

Gold, D., Simson, H., \& Zuvela, B. (2005). An unequal playing field: Report on the needs of people living in Canada who are blind or visually impaired. Toronto: CNIB.

Heuten, W., Henze, N., Boll, S., \& Pielot, M. (2008). Tactile wayfinder: A non-visual support system for wayfinding. In K. Tolmar \& B. Jönsson (Eds). Proceedings of the $5^{\text {th }}$ Nordic Conference on Human-Computer Interaction (pp. 172-181), Lund, Sweden : ACM Press, October 20-22.

Ho, C. \& Spence, C. (2008) The Multisensory Driver: Implications for ergonomic car interface design. Aldershot: Ashgate. ISBN: 9780754670681. 
Iachini, T., Ruggiero, G., \& Ruotolo, F. (2014). Does blindness affect egocentric and allocentric frames of reference in small and large scale spaces? Behavorial Brain Research, 273, 73-81.

Kammoun, S. (2013). Assistance à la navigation pour les non-voyants : vers un positionnement, un SIG et un suivi adaptés. Thèse de doctorat, Spécialité Informatique, université de Toulouse III.

Katz, B., Kammoun, S., Parseihian, G., Gutierrez, O., Brilhault, A., Auvray, M., Truillet, P., Thorpe, S., \& Jouffrais, C. (2012a). NAVIG: Augmented reality guidance system for the visually impaired. Virtual Reality fournal, 16, 253269.

Katz, B., Dramas, F., Parseihian, G., Gutierrez, O., Kammoun, S., Brilhault, A., Brunet, L., Gallay, M., Oriola, B., Auvray, M., Truillet, P., Thorpe, S., \& Jouffrais, C. (2012b). NAVIG guidance system for the visually impaired using virtual augmented reality. Technology and Disability, 24, 163-178.

Kessler, K., \& Thomson, L. A. (2010). The embodied nature of spatial perspective taking: Embodied transformation versus sensorimotor interference. Cognition, $114,72-88$.

Kessler, K., \& Wang, H. (2012). Spatial perspective taking is an embodied process, but not for everyone in the same way: differences predicted by sex and social skills score. Spatial Cognition \& Computation, 12, 133-158.

Klatzky, R.L, Giudice, N.A., Bennett, C.R., \& Loomis, J.M. (2014). Touch-screen technology for the dynamic display of $2 \mathrm{D}$ spatial information without vision: Promise and progress. Multisensory Research, 27, 359-378.

Leplat J. (1990). Relations between task and activity: elements for elaborating a framework for error analysis. Ergonomics, 33, 10-11.

Loomis, J. \& Philbeck, W. (2008). Measuring Spatial Perception with Spatial Updating and Action. In R.L. Klatzky, B. MacWhinney and M.Behrmann (Eds.). Embodiment, Ego-space, and Action (pp. 1-44). Mahwah, NJ: Lawrence Erlbaum Associates.

Loomis, J., Marston, J., Golledge, R., \& Klatzky, R. (2005). Personal guidance system for visually impaired people: Comparison of spatial displays for route guidance. Fournal of Visual Impairment and Blindness, 99, 219-232.

Loomis, J.M., Klatzky, L., Golledge, R., Cicinelli, J., Pellegrino, J., \& Fry, F. (1993). Nonvisual Navigation by Blind and Sighted: Assessment of Path Integration Ability. Fournal of Experimental Psychology: General, 122, 73-91.

Mekhalfi, M. L., Melgani, F., Zeggada, A., De Natale, F. G. B., Salem, M. A.-M., \& Khamis, A. (2016). Recovering the Sight to Blind People in Indoor Environments with Smart Technologies. Expert Systems with Applications, 46, 129-138.

Miele, J., Landau, S., \& Gilden, D. (2006). Talking TMAP: Automated Generation of Audio-Tactile Maps Using Smith-Kettlewell's TMAP Software. The British journal of Visual Impairment, 24, 93-100.

Nelson, J., Wolff, M., Cabon, P., Uzan, G., \& Couix, S. (2006). Déplacements urbains de personnes non-voyantes : la fréquence cardiaque comme indicateur potentiel de stress [Urban mobility of blind people: heart rate as a potential stress indicator]. Proceedings of the ERGO-IA Conference (pp. 376-377), Biarritz, France, October 11-13.

Noordzij, M.L., Zuidhoek, S., \& Postma, A. (2007). The influence of visual experience on visual and spatial Imagery. Perception $\mathcal{E}$ Psychophysics, 36, 101-112.

O'Brien, J. \& Auvray, M. (2014). The process of distal attribution illuminated through studies of sensory substitution. Multisensory Research, 27, 421-441.

O'Keefe, J. \& Nadel, L. (1978). The Hippocampus as a Cognitive Map. Oxford : Clarendon Press.

Ochanine, D. (1978). Le rôle des images opératives dans la régulation des activités de travail [The role of operative images in the regulation of work activities]. Psychologie et Education, 3, 63-79. 
Plos. O, Buisine. S., Aouassat. A., \& Dumas. C. (2007). Analysis and translation of user needs for assistive technology design. Proceedings of the International Conference on Engineering Design, ICED’07 (pp. 500-506), August 28-31, Paris, France.

Proulx, M. J., Todorov, O., Taylor Aiken, A., \& de Sousa, A. (2016). Where am I? Who am I? The relation between spatial and social cognition in the built environment. Frontiers in Psychology, 7. doi=10.3389/fpsyg.2016.00064

Richard, F., Vaz-Cemiglia, C., \& Portalier, S. (2004). Evolution des procédures d'exploration haptique chez des sujets voyants, aveugles tardifs et aveugles précoces [Evolution of the processes of haptic exploration in sighted, early and late blind subjects]. European Review of Applied Psychology, 54, 227-236.

Rieser, J. J., Gum, D. A., \& Hill, E. W. (1986). Sensitivity to perspective structure while walking without vision. Perception, 15, 173-188.

Sanchez, J. \& Saenz, M. (2010). Metro navigation for the blind. Computers E Education, 55(3), 970-981. doi.org/10.1016/j.compedu.2010.04.008

Schinazi, V.R., Thrash, T., \& Chebat, D.R. (2016). Spatial navigation by congenitally blind individuals. Wiley Interdisciplinary Reviews: Cognitive Science, 7(1), 37-58.

Spérandio, J-C. \& Uzan, G. (2004). Ergonomie des aides techniques informatiques pour personnes handicapées [Ergonomy of technical computer aids for disabled people]. In P. Falzon (Ed.), Ergonomie (pp. 479-496). Paris: PUF.

Thinus-Blanc, C. \& Gaunet, F. (1997). Representation of space in blind persons: Vision as a spatial sense? Psychological Bulletin, 121(1), 20-42.

Wolff, M., Cabon, P., Uzan, G., Nelson, J., \& Couix, S. (2006). Déplacements urbains de personnes non-voyantes : étude multifactorielle des difficultés et apports d'une nouvelle interface pour le recueil de données [Urban mobily of blind people: multifactorial study of difficulties and contributions of a new interface for data collection]. Proceedings of the ERGO-IA Conference (pp. 277-386), October 11-13, Biarritz, France.

World Health Organization (WHO, 2017). Vision impairment and blindness. Fact Sheet \#282, Updated October 2017. Retrieved February 23 - www.who.int/ mediacentre/factsheets/fs282/en/ 